\title{
PSMA3-AS1 induced by transcription factor PAX5 promotes cholangiocarcinoma proliferation, migration and invasion by sponging miR-376a-3p to up-regulate LAMC1
}

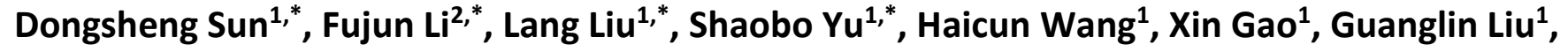 \\ Yuqiao Zhao ${ }^{1}$, Gongcai Qiu ${ }^{1}$, Xingming Jiang ${ }^{1}$ \\ ${ }^{1}$ Department of General Surgery, The Second Affiliated Hospital of Harbin Medical University, Harbin 150086, China \\ ${ }^{2}$ Department of General Surgery, South China Hospital, Health Science Center, Shenzhen University, Shenzhen \\ 518116, China \\ *Equal contribution
}

Correspondence to: Xingming Jiang; email: xmjiang@hrbmu.edu.cn Keywords: PSMA3-AS1, cholangiocarcinoma, IncRNA, miR-376a-3p, LAMC1

Received: September 15, 2021 Accepted: December 29, $2021 \quad$ Published: January 12, 2022

Copyright: (C) 2022 Sun et al. This is an open access article distributed under the terms of the Creative Commons Attribution License (CC BY 3.0), which permits unrestricted use, distribution, and reproduction in any medium, provided the original author and source are credited.

\section{ABSTRACT}

Long noncoding RNAs (IncRNAs) have been reported to exhibit a crucial regulatory role in tumor progression, including cholangiocarcinoma (CCA). As a promising IncRNA, proteasome 20S subunit alpha 3 antisense RNA 1 (PSMA3-AS1) is involved in development of various tumors. However, the role and function of PSMA3-AS1 in CCA remain unclear. The aim of this study is to examine the expression, function, mechanism, and clinical significance of PSMA3-AS1 in CCA development. By TCGA database analysis, we found that PSMA3-AS1 was overexpressed in CCA. Consistent with the TCGA analysis, PSMA3-AS1 was significantly overexpressed in CCA tissues and cells by RT-qPCR. Upregulated PSMA3-AS1 was related to lymph node invasion, advanced TNM stage and poor survival, and was an independent risk factor of prognosis for CCA patients. Functionally, CCK-8, EdU and colony formation assays confirmed that upregulated PSMA3-AS1 promoted CCA cell proliferation, whereas downregulated PSMA3-AS1 inhibited proliferation. This result was further confirmed by subcutaneous tumor formation in nude mice. Wound healing and transwell assays confirmed that increased PSMA3-AS1 promoted CCA cell migration and invasion, whereas decreased PSMA3-AS1 inhibited these biological phenotypes. In addition, PSMA3-AS1 promoted the EMT process of CCA by downregulating E-cadherin and upregulating $\mathrm{N}$-cadherin and vimentin. Mechanistically, transcription factor PAX5 bound to the promoter region of PSMA3-AS1 and promoted its transcription. Simultaneously, PSMA3-AS1 primarily localized in the cytoplasm could competitively bind miR-376a-3p to upregulate LAMC1, thereby accelerating CCA progression. This study uncovers that PSMA3-AS1 functions as a cancer-promoting gene in CCA, and PAX5/PSMA3-AS1/miR-376a3p/LAMC1 axis plays a vital role in CCA development.

\section{INTRODUCTION}

Cholangiocarcinoma (CCA) is a malignant tumor that happens in the biliary tree. In recent years, the incidence of CCA is gradually increased, especially in Thailand [1]. CCA has a high malignant degree and an insidious incidence. Due to the lack of sensitive and specific early diagnostic markers, most patients were already the later period of the carcinoma [2]. Thus they lost the opportunity for radical surgery. The longterm survival and prognosis of patients with CCA were quite poor [3]. Accordingly, exploring new tumor markers is urgently needed, and finding new anticancer targets for CCA patients with advanced 
stage is also a practical problem that needs to be solved clinically.

Long noncoding RNA (lncRNA) is a linear RNA molecule longer than $200 \mathrm{nt}$ [4]. They are not able to encode proteins owing to absence of full ORF [5]. LncRNAs are involved in gene expression regulation in the form of RNA and particularly exert crucial action in tumorigenesis, including $\mathrm{CCA}[6,7]$. For instance, IncRNA HOXD-AS1 promoted CCA cell growth and metastasis through adsorbing miR-520c-3p [4]; lncRNA MEG3 was downexpressed and suppressed cellular malignant biological behaviors in CCA [8]. Proteasome 20S subunit alpha 3 antisense RNA 1 (PSMA3-AS1) is a tumor-related IncRNA located on chromosome 14q23.1 [9]. PSMA3-AS1 is an oncogene and exerts pro-cancer function in colorectal cancer, esophageal cancer and glioma [10-12]. For example, PSMA3-AS1 boosted metastasis of colorectal cancer cell by restraining miR-4429 [10]; PSMA3-AS1 adsorbed miR101 to promote esophageal tumor development [11]. Nevertheless, function and mechanism of PSMA3-AS1 in CCA are still obscure.

The paired box 5 (PAX5) belongs to paired box domain family, which is mapping to 9p13 [13]. The aberrant expression of PAX5 is associated with multiple carcinomas [14]. For example, PAX5 as transcription factor induced the overexpression of IDH1-AS1 to promote prostate tumor proliferation [15]. The laminin subunit gamma 1 (LAMC1) is a member of laminin family. It is involved in basement membrane reestablishment and cancer invasion [16]. For instance, LAMC1 boosted tumor cell proliferation and inhibited cell death in hepatocellular carcinoma [17]. The correlation of PSMA3-AS1, PAX5 and LAMC1, as well as their function in CCA is not reported and requires further investigation.

The present study confirmed a significantly high expression of PSMA3-AS1 in CCA. Elevating PSMA3AS1 was linked to clinicopathological characteristics and worse survival. Furthermore, PSMA3-AS1 competitively adsorbed miR-376a-3p to upregulate LAMC1, thereby promoting CCA cell growth and metastasis. In addition, PSMA3-AS1 was transcriptionally activated by PAX5. These findings suggest that PSMA3-AS1 is expected to become viable intervention target in CCA.

\section{RESULTS}

\section{PSMA3-AS1 expression in CCA and the association with survival}

Via TCGA database analysis, we found that PSMA3AS1 was highly expressed in cholangiocarcinoma $(P<$
0.001, Figure 1A). Therefore, we decided to further investigate its role in CCA. By RT-qPCR detection, PSMA3-AS1 was indeed highly expressed in cholangiocarcinoma tissues and cells (Figure 1B, 1C). In the light of average value of PSMA3-AS1 expression, we divided 66 CCA patients into two sets. Clinicopathological correlation analysis showed that highly expressed PSMA3-AS1 was linked to advanced TNM stage and lymph node invasion of CCA patients (Table 1). Kaplan-Meier survival curve displayed that elevating PSMA3-AS1 patients possessed shorter survival time (log rank $P<0.001$, Figure 1D). Pearson correlation analysis further confirmed a negative correlation of PSMA3-AS1 expression and survival time $(\mathrm{r}=-0.4915, P<0.001$, Figure $1 \mathrm{E})$. The univariate COX regression analysis showed that PSMA3-AS1, lymph node invasion, and advanced TNM stage were related to overall survival, and multivariate analysis further revealed that PSMA3-AS1 expression as well as advanced TNM stage was an independent risk factor for prognosis (Table 2). The ROC curve revealed that AUC value of PSMA3-AS1 as prognostic marker was 0.793 (95\% CI: 0.668-0.919) with $70.8 \%$ sensitivity and $79.2 \%$ specificity $(P<0.001$, Figure $1 \mathrm{~F})$. These results suggest that highly expressed PSMA3-AS1 is significantly linked to survival, and can serve as an effective indicator for prognostic evaluation. In addition, the interference efficiency of si-PSMA3-AS1 and oe-PSMA3-AS1 were detected for next cytology experiments (Supplementary Figure 1A).

\section{PSMA3-AS1 boosted cholangiocarcinoma growth and metastasis}

In the light of PSMA3-AS1 expression analysis in the four cholangiocarcinoma cells, PSMA3-AS1 level was the highest in CCLP-1 and the lowest in QBC939 cells. Therefore, to obtain a more logical experimental result, we chose to knock down PSMA3-AS1 in CCLP-1 to execute loss-of-function assays, and chose to overexpress it in QBC939 to perform gain-of-function assays. Proliferation experiments confirmed that silencing PSMA3-AS1 depressed cellular vitality, whereas elevating PSMA3-AS1 enhanced cellular vitality (Figure 2A, 2B). Colony formation assay corroborated that PSMA3-AS1 facilitated the colonyforming ability of cholangiocarcinoma cells (Figure 2C). To examine effect of PSMA3-AS1 on CCA proliferation in vivo, we established subcutaneous tumor xenograft model ( $n=6$ per group). Silencing PSMA3AS1 significantly inhibited tumor growth compared with negative control groups (Figure 2D), including the volume (Figure 2E) and weight (Figure 2F) of the tumors. Whereafter, silencing PSMA3-AS1 depressed cholangiocarcinoma migration, whereas elevating PSMA3-AS1 boosted cell migration (Figure 2G, 2H). 
Table 1. Correlation between PSMA3-AS1 expression and clinicopathological characteristics of CCA patients.

\begin{tabular}{|c|c|c|c|c|}
\hline \multirow{2}{*}{ Clinicopathological parameters } & \multirow{2}{*}{ Total } & \multicolumn{2}{|c|}{ PSMA3-AS1 expression } & \multirow{2}{*}{$P$-value } \\
\hline & & Low & High & \\
\hline \multicolumn{5}{|l|}{ Age (years) } \\
\hline$<60$ & 19 & 11 & 8 & \multirow{2}{*}{0.106} \\
\hline$\geq 60$ & 47 & 17 & 30 & \\
\hline \multicolumn{5}{|l|}{ Gender } \\
\hline Male & 29 & 14 & 15 & \multirow{2}{*}{0.394} \\
\hline Female & 37 & 14 & 23 & \\
\hline \multicolumn{5}{|l|}{ Differentiation grade } \\
\hline Well/moderate & 28 & 15 & 13 & \multirow{2}{*}{0.116} \\
\hline Poor/undifferentiated & 38 & 13 & 25 & \\
\hline \multicolumn{5}{|l|}{ Serum CA19-9 level } \\
\hline$\leq 37 \mathrm{U} / \mathrm{ml}$ & 25 & 13 & 12 & \multirow{2}{*}{0.219} \\
\hline$>37 \mathrm{U} / \mathrm{ml}$ & 41 & 15 & 26 & \\
\hline \multicolumn{5}{|l|}{ Serum CEA level } \\
\hline$\leq 5 \mathrm{ng} / \mathrm{ml}$ & 23 & 13 & 10 & \multirow{2}{*}{0.090} \\
\hline$>5 \mathrm{ng} / \mathrm{ml}$ & 43 & 15 & 28 & \\
\hline \multicolumn{5}{|l|}{ TNM stage } \\
\hline I-II & 20 & 13 & 7 & \multirow{2}{*}{$0.014^{*}$} \\
\hline III-IV & 46 & 15 & 31 & \\
\hline \multicolumn{5}{|l|}{ Lymph node invasion } \\
\hline No & 27 & 16 & 11 & \multirow{2}{*}{$0.021^{*}$} \\
\hline Yes & 39 & 12 & 27 & \\
\hline
\end{tabular}

${ }^{*} P<0.05$. Abbreviations: PSMA3-AS1: proteasome subunit $\alpha 3$ antisense RNA 1; CCA: cholangiocarcinoma; CA19-9: carbohydrate antigen 19-9; CEA: carcinoembryonic antigen.

Table 2. Univariate and multivariate analysis for overall survival of CCA patients.

\begin{tabular}{|c|c|c|c|c|c|c|}
\hline \multirow{2}{*}{ Variables } & \multicolumn{3}{|c|}{ Univariate analysis } & \multicolumn{3}{|c|}{ Multivariate analysis } \\
\hline & HR & $95 \% \mathrm{CI}$ & $P$-value & HR & $95 \% \mathrm{CI}$ & $P$-value \\
\hline $\begin{array}{l}\text { Age (years) } \\
\geq 60 \text { vs. }<60\end{array}$ & 1.579 & $0.900-2.768$ & 0.111 & & & \\
\hline $\begin{array}{l}\text { Gender } \\
\text { Male vs. Female }\end{array}$ & 1.331 & $0.753-2.354$ & 0.325 & & & \\
\hline $\begin{array}{l}\text { Differentiation grade } \\
\text { Poor/undifferentiated vs. Well/moderate }\end{array}$ & 1.436 & $0.840-2.453$ & 0.186 & & & \\
\hline $\begin{array}{l}\text { Serum CA19-9 level } \\
>37 \mathrm{U} / \mathrm{ml} \text { vs. } \leq 37 \mathrm{U} / \mathrm{ml}\end{array}$ & 1.364 & $0.764-2.434$ & 0.294 & & & \\
\hline $\begin{array}{l}\text { Serum CEA level } \\
>5 \mathrm{ng} / \mathrm{ml} \text { vs. } \leq 5 \mathrm{ng} / \mathrm{ml}\end{array}$ & 1.517 & $0.879-2.620$ & 0.135 & & & \\
\hline $\begin{array}{l}\text { TNM stage } \\
\text { III-IV vs. I-II }\end{array}$ & 1.893 & $1.100-3.258$ & $0.021^{*}$ & 2.145 & $1.182-3.892$ & $0.012^{*}$ \\
\hline $\begin{array}{l}\text { Lymph node invasion } \\
\text { Yes vs. No }\end{array}$ & 1.852 & $1.045-3.282$ & $0.035^{*}$ & 1.686 & $0.969-2.935$ & 0.065 \\
\hline $\begin{array}{l}\text { PSMA3-AS1 expression } \\
\text { Low vs. High }\end{array}$ & 2.059 & $1.159-3.658$ & $0.014^{*}$ & 2.195 & $1.246-3.867$ & $0.006^{* *}$ \\
\hline
\end{tabular}

${ }^{*} P<0.05,{ }^{* *} P<0.01$. Abbreviations: CCA: cholangiocarcinoma; HR: hazard ratio; Cl: confidence interval; CA19-9: carbohydrate antigen 19-9; CEA: carcinoembryonic antigen; PSMA3-AS1: proteasome subunit $\alpha 3$ antisense RNA 1.

Transwell invasion assay pre-coated with Matrigel further uncovered that PSMA3-AS1 facilitated CCA cell invasion in comparison with control groups (Figure
2I). Vimentin and N-cadherin represented EMT-related mesenchymal markers, and E-cadherin represented EMT-related epithelial marker. As shown in Figure 2J, 
knocking down PSMA3-AS1 significantly inhibited vimentin and $\mathrm{N}$-cadherin, but facilitated E-cadherin in CCLP-1. On the contrary, overexpressed PSMA3-AS1 promoted vimentin and $\mathrm{N}$-cadherin expression, whereas depressed E-cadherin in QBC939 cells. Thus, PSMA3AS1 accelerated the EMT process of CCA. The above functional experiments suggest that PSMA3-AS1 boosts growth and metastasis of cholangiocarcinoma.

\section{PAX5 transcriptionally activated and enhanced PSMA3-AS1 expression}

We applied JASPAR database (http://jaspar. genereg.net/) to detect the transcriptional regulatory molecules of PSMA3-AS1, and found two PAX5 binding sites in PSMA3-AS1 promoter (Figure 3A). Therefore, we decided to examine their interrelationship. Firstly, we knocked down and overexpressed PAX5 via si-PAX5 and pcDNA3.1PAX5, and obtained satisfactory knockdown efficiency and amplification efficiency (Figure 3B, 3C). As shown in Figure 3D, knocking down PAX5 significantly inhibited PSMA3-AS1 expression, whereas elevating PAX5 promoted PSMA3-AS1 expression. Next, PAX5 level was increased in CCA tissues both at mRNA and protein level (Figure 3E, 3F). PAX5 expression was positively linked to PSMA3-AS1 $(r=0.4836, P<$ 0.001, Figure 3G). High PAX5 expression in CCA cells was also confirmed (Figure 3H, 3I). In addition, we found that knocking down PAX5 inhibited vimentin and $\mathrm{N}$-cadherin, but facilitated E-cadherin in CCLP-1 (Supplementary Figure 1B); overexpressed PAX5 promoted vimentin and $\mathrm{N}$-cadherin expression, but suppressed E-cadherin in QBC939 (Supplementary Figure 1C). This result illustrated that PAX5 promoted the EMT process of CCA. Chromatin immunoprecipitation (ChIP) confirmed that only binding site 1 responded to PAX5-mediated transcription (Figure 3J). Luciferase reporter experiment further confirmed that elevating PAX5 only strengthened luciferase activity of binding site 1 wild type (Figure 3K). Above findings illustrate that PAX5 expression is upregulated in CCA, and can activate and enhance PSMA3-AS1 transcription.

\section{PSMA3-AS1 adsorbed and repressed miR-376a-3p in CCA}

PSMA3-AS1 was predominantly expressed in CCA cytoplasm (Figure 4A), so we predicted its downstream target genes functioning through ceRNA patterns at the post-transcriptional level via StarBase database. By examining effects of knockdown and overexpression of PSMA3-AS1 on the target miRNAs, we found that knocking down PSMA3-AS1 significantly increased miR-376a-3p level, but overexpressing PSMA3-AS1
A

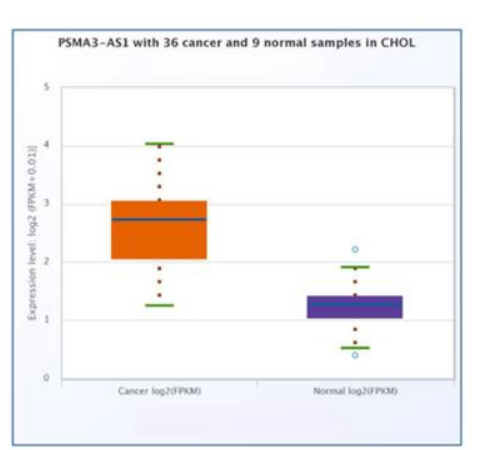

D

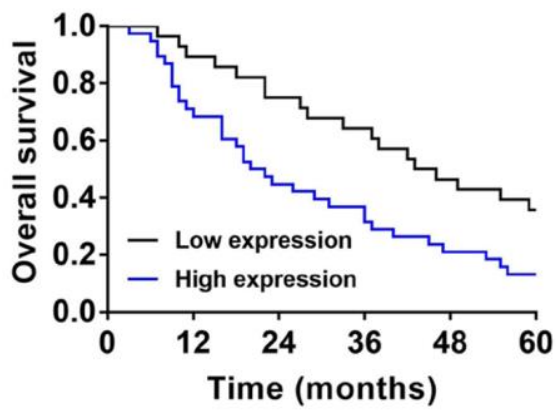

B

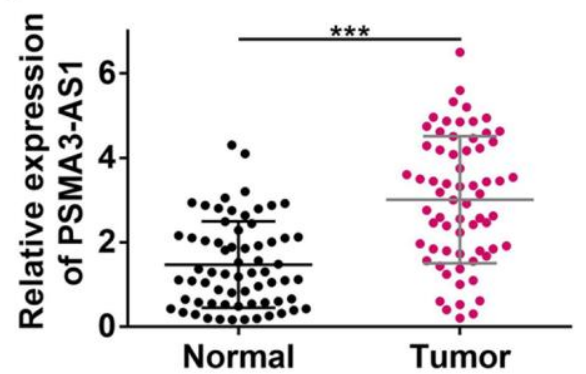

E

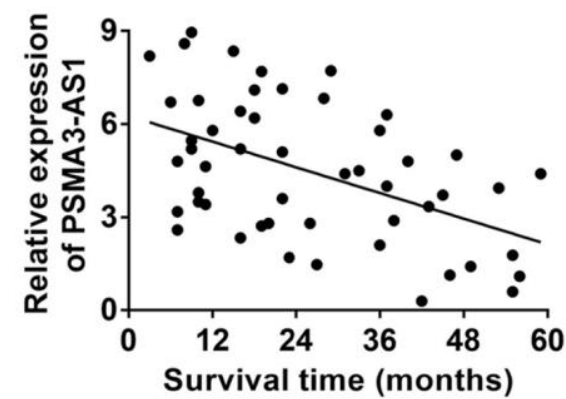

C

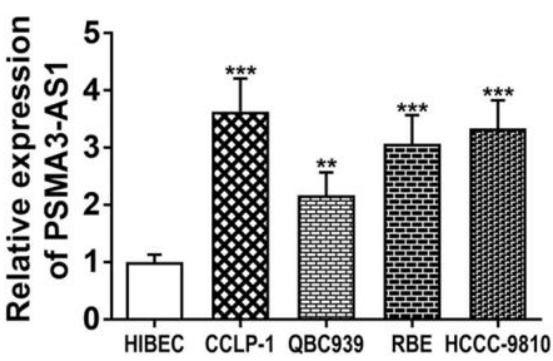

$\mathbf{F}$

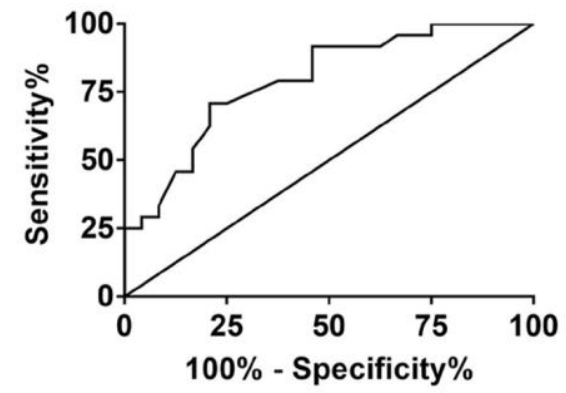

Figure 1. PSMA3-AS1 expression and its association with clinicopathological characteristics. (A) PSMA3-AS1 expression in TCGA database. (B) PSMA3-AS1 expression in CCA tissues and paired adjacent tumor-free bile duct tissues. (C) PSMA3-AS1 expression in CCA cells. (D) Kaplan-Meier curves analyzed the survival correlation. (E) Pearson correlation analysis examined the linear correlation of PSMA3AS1 expression and survival time. (F) ROC curve assessed the potential of PSMA3-AS1 as a prognostic marker. ${ }^{* *} P<0.01,{ }^{* * *} P<0.001$. 
significantly decreased miR-376a-3p (Figure 4B). MiR376a-3p expression was downregulated in CCA tissues (Figure 4C), and negatively related to PSMA3-AS1 expression $(\mathrm{r}=-0.4969, P<0.001$, Figure 4D). MiR376a-3p was also downregulated in cholangiocarcinoma cells (Figure 4E). The knockdown efficiency and
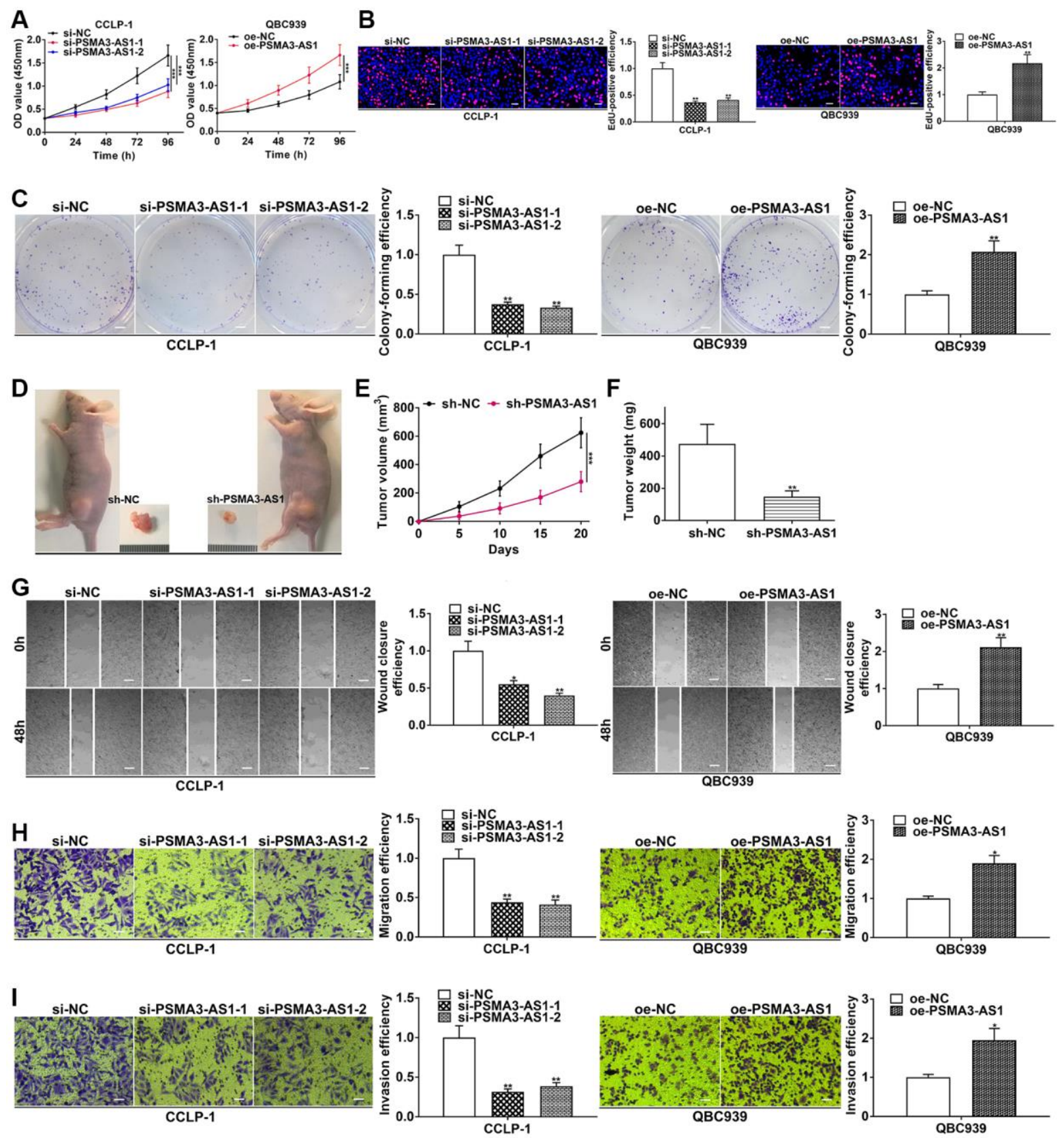

J
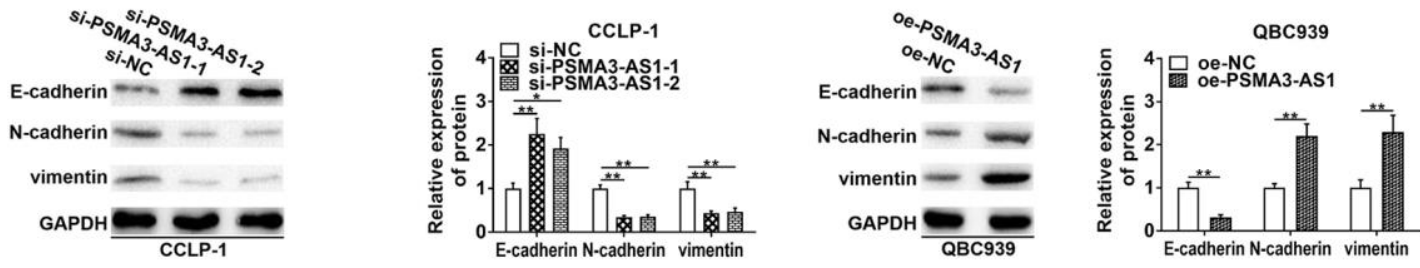

Figure 2. PSMA3-AS1 promotes CCA cell proliferation, invasion and EMT. (A) CCK-8 and (B) EdU assays determined the effect of PSMA3-AS1 on CCA proliferation. (C) Colony formation assay determined the effect of PSMA3-AS1 on colony-forming ability of CCA cells. (D) The effect of PSMA3-AS1 on CCA proliferation in vivo. (E) Knocking down PSMA3-AS1 restrained the tumor volume and (F) tumor weight in nude mice. (G) Wound healing and $(\mathbf{H}, \mathbf{I})$ transwell assays validated the effects of PSMA3-AS1 on migration and invasion of CCA cells. (J) The effect of PSMA3-AS1 on EMT process of CCA cells. ${ }^{*} P<0.05,{ }^{* *} P<0.01,{ }^{* * *} P<0.001$. 
overexpression efficiency of miR-376a-3p inhibitor and mimics were shown in Figure 4F. Elevating miR-376a$3 p$ only repressed luciferase activity of PSMA3-AS 1 wild type (Figure 4G, 4H). AGO2 RNA immunoprecipitation (RIP) demonstrated that PSMA3AS1 directly adsorbed miR-376a-3p (Figure 4I). Besides, overexpressing miR-376a-3p depressed growth and metastasis of cholangiocarcinoma, but knocking
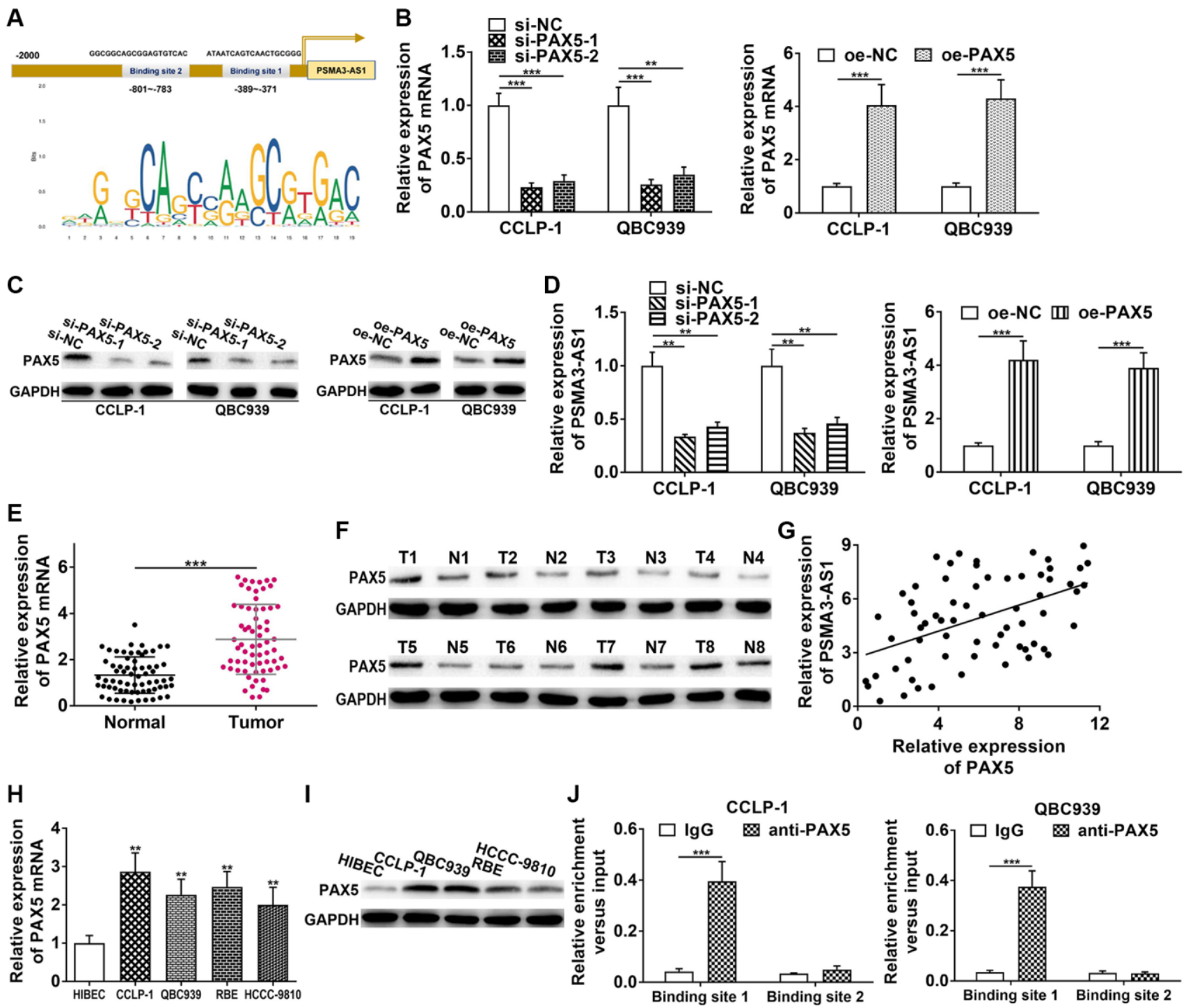

I
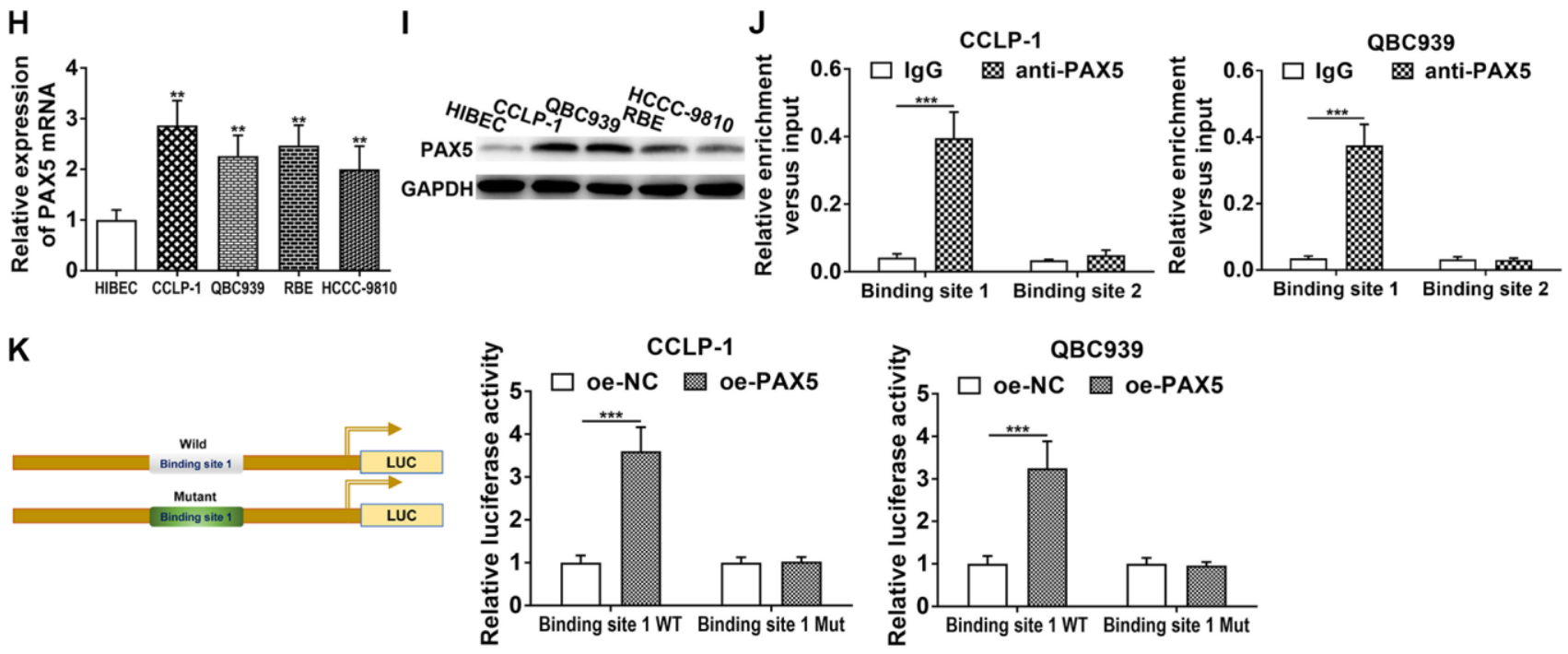

Figure 3. PAX5 transcriptionally activates and enhances PSMA3-AS1 expression. (A) JASPAR database detected the binding sites of PAX5 and PSMA3-AS1. (B) Knockdown efficiency and amplification efficiency of PAX5 in CCA cells both at mRNA and (C) protein level. (D) PAX5 regulated PSMA3-AS1 expression. (E) The expression of PAX5 in CCA tissues both at mRNA and (F) protein level. (G) PAX5 expression was positively correlated with PSMA3-AS1 expression. (H) The expression of PAX5 in CCA cells both at mRNA and (I) protein level. (J) ChIP assay confirmed that the binding site 1 of PSMA3-AS1 promoter was responsive to PAX5-induced transcription, but no obvious changes in binding site 2. (K) Luciferase reporter assay confirmed that the luciferase activity of the wild type of binding site 1 was increased by elevating PAX5, but no significant change in mutant type group. ${ }^{* *} P<0.01,{ }^{* * *} P<0.001$. 
down miR-376a-3p promoted these malignant biological behaviors (Figure 5). The above results indicate that PSMA3-AS1 adsorbs miR-376a-3p to accelerate CCA deterioration.

\section{miR-376a-3p targeted LAMC1 in CCA}

StarBase v3.0 database showed that PSMA3-AS1 had overlapping binding sites with LAMC1 at miR-376a-3p sequences (Supplementary Figure 1D). Hence, we determined to validate regulatory relationship of miR376a-3p and LAMC1. As shown in Figure 6A and 6B, si-LAMC1 significantly inhibited LAMC1 expression, while pcDNA3.1-LAMC1 significantly enhanced LAMC1. Furthermore, miR-376a-3p mimics decreased LAMC1 expression and miR-376a-3p inhibitor increased LAMC1 level in CCA cells (Figure 6C, 6D). Moreover, silencing PAX5 restrained LAMC1 expression and overexpressing PAX5 facilitated LAMC1 expression (Supplementary Figure 1E). TCGA
A
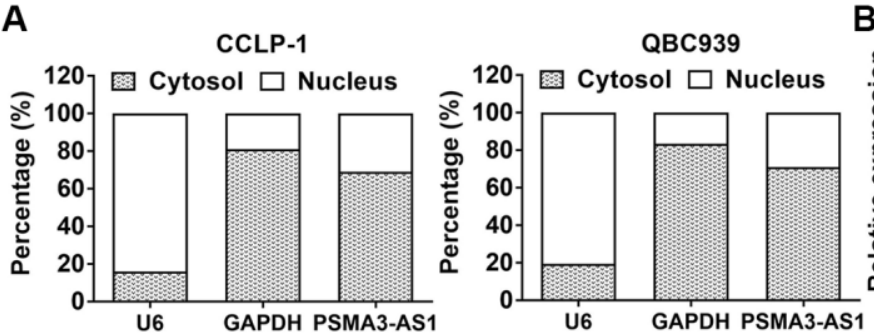

C

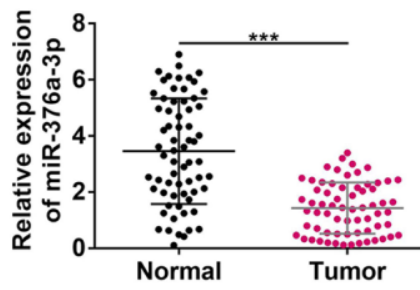

$\mathbf{F}$

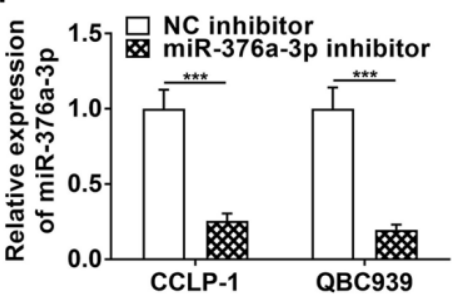

D
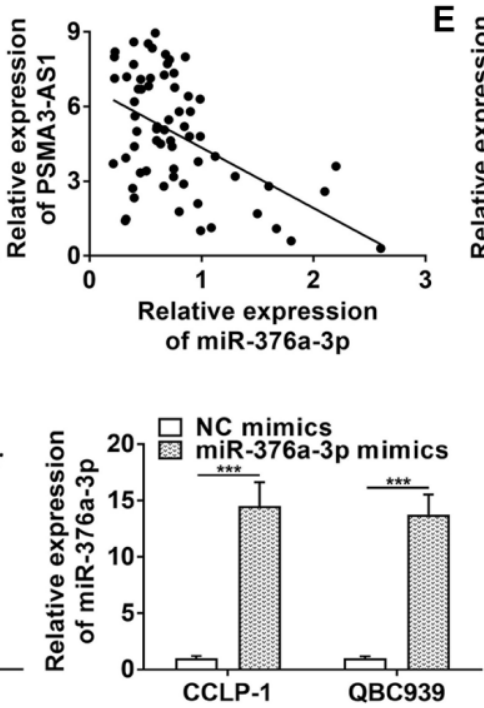

E
B
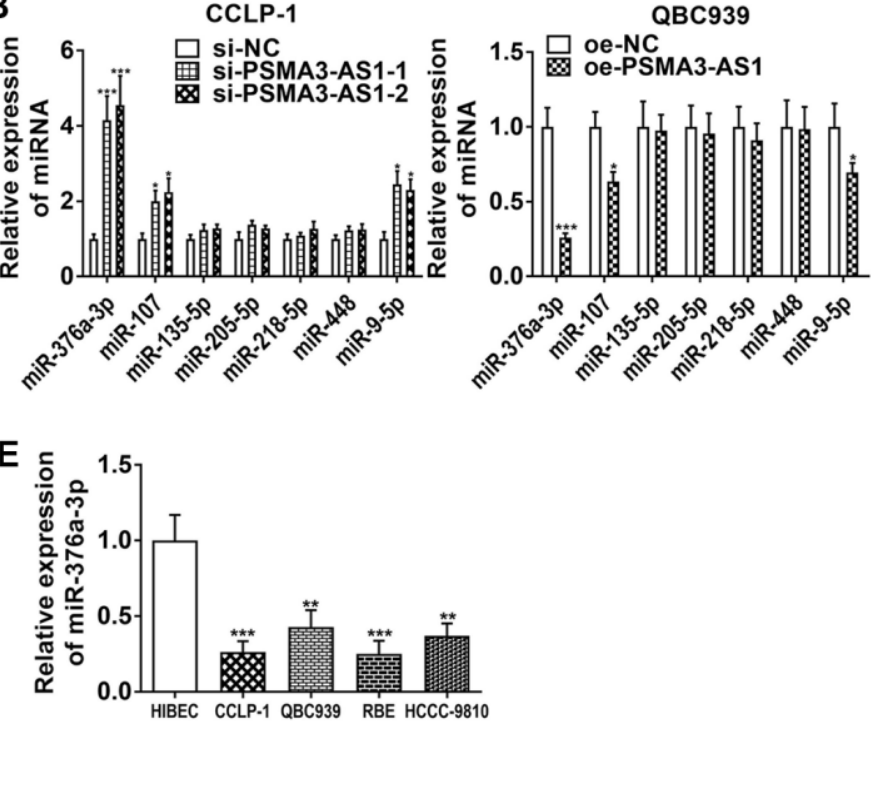

G

PSMA3-AS1 Wild 5' aaauccacagcCAUCUAUGAa 3' miR-376a-3p 3' ugcaccuaaaaGGAGAUACÚa 5' PSMA3-AS1 Mutant 5' aaauccacagcGAAGAUACUa 3'
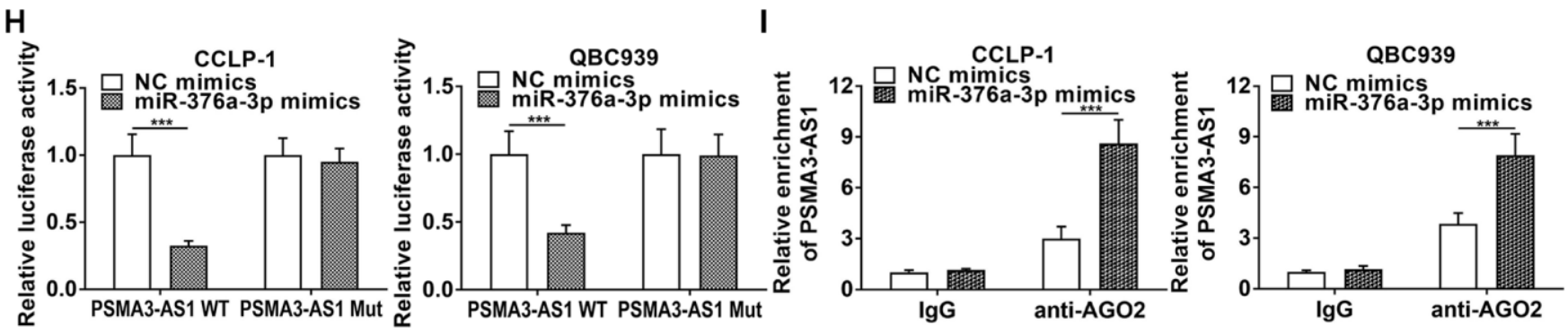

Figure 4. PSMA3-AS1 competitively binds to miR-376a-3p in CCA cells. (A) Subcellular fractionation assay showed that PSMA3-AS1 was mainly expressed in the cytoplasm of CCA cells. (B) PSMA3-AS1 dramatically inhibited miR-376a-3p expression in CCA cells. (C) The expression of miR-376a-3p in CCA tissues. (D) miR-376a-3p expression was negatively correlated with PSMA3-AS1 expression. (E) The expression of miR-376a-3p in CCA cells. (F) Knockdown efficiency and amplification efficiency of miR-376a-3p in CCA cells. (G, H) The luciferase reporter assay indicated that the luciferase activity of PSMA3-AS1 wild type was repressed by co-transfection with miR-376a-3p mimics, but the luciferase activity of PSMA3-AS1 mutant type was not affected. (I) AGO2 RIP assay further demonstrated the direct interaction between PSMA3-AS1 and miR-376a-3p. ${ }^{*} P<0.05,{ }^{* *} P<0.01,{ }^{* * *} P<0.001$. 
displayed that LAMC1 was upregulated in cholangiocarcinoma (Figure 6E). Authentically, LAMC1 was overexpressed in CCA tissues (Figure 6F, $6 \mathrm{G})$, and negatively related to miR-376a-3p ( $\mathrm{r}=$
$-0.4561, P<0.001$, Figure 6H). Nevertheless, LAMC1 was positively related to PAX5 $(\mathrm{r}=0.4457, P<0.001$, Supplementary Figure 1F). LAMC1 was also elevated in cholangiocarcinoma cells (Figure 6I, 6J).
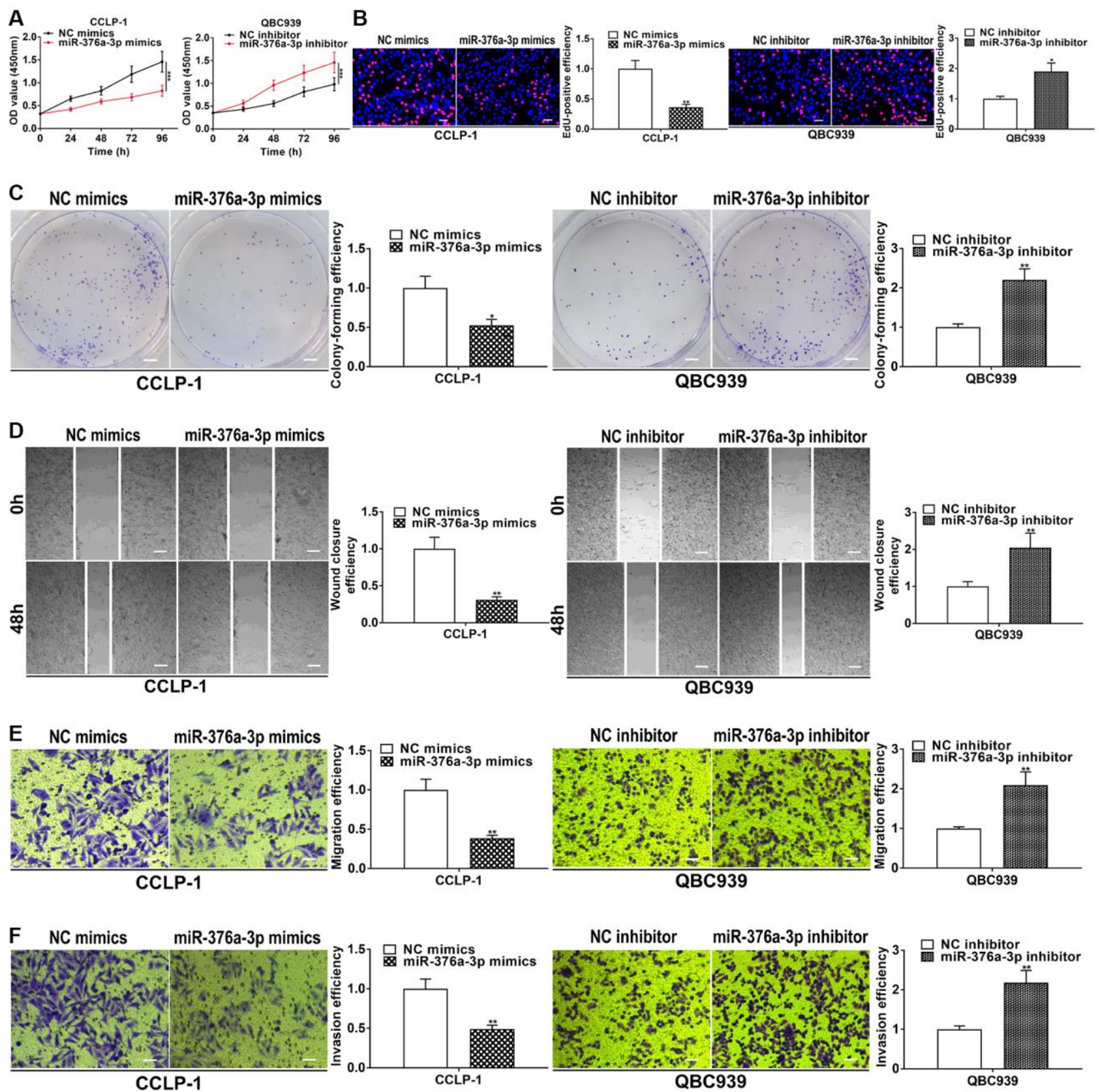

G

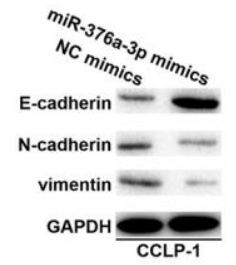

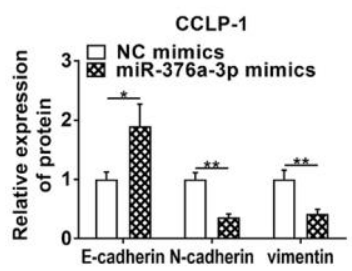
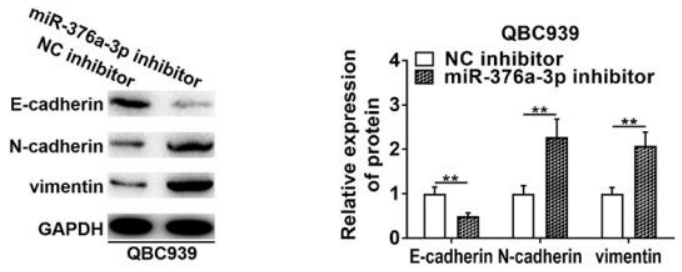

Figure 5. miR-376a-3p represses CCA cell proliferation, invasion and EMT. (A) CCK-8 and (B) EdU assays determined the effect of miR-376a-3p on CCA proliferation. (C) Colony formation assay determined the effect of miR-376a-3p on colony-forming ability of CCA cells. (D) Wound healing and (E, F) transwell assays validated the effects of miR-376a-3p on migration and invasion of CCA cells. (G) The effect of miR-376a-3p on EMT process of CCA cells. ${ }^{*} P<0.05,{ }^{* *} P<0.01,{ }^{* * *} P<0.001$. 
We implemented luciferase reporter assay and RIP assay to demonstrate complementary binding of miR-376a-3p and LAMC1. Wild and mutant type of LAMC1 3'UTR were constructed into luciferase plasmids, respectively
(Figure 6K). Elevating miR-376a-3p reduced the luciferase activity of LAMC1 wild type rather than mutant (Figure 6L). Furthermore, RIP uncovered that LAMC1 was augmented via anti-AGO2 antibody
A

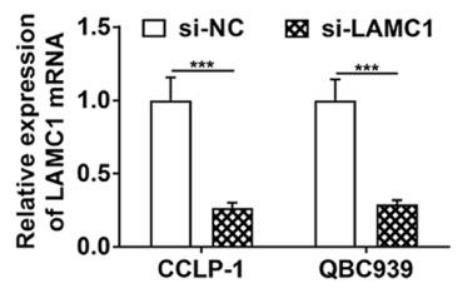

C

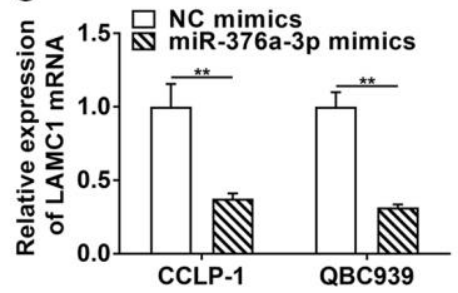

E

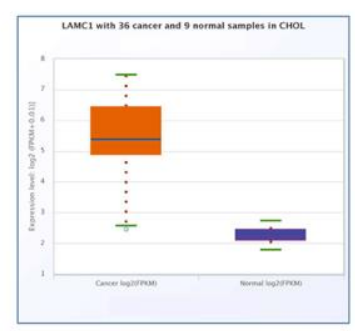

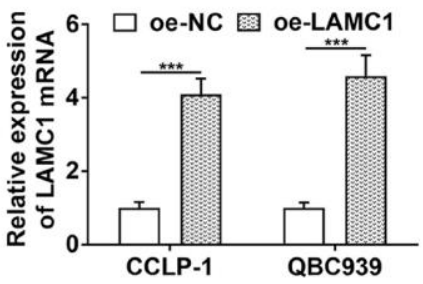

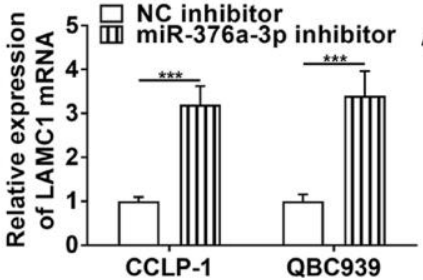

$\mathbf{F}$

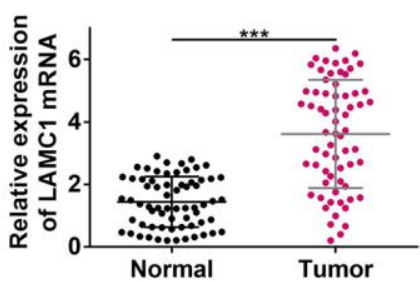

B
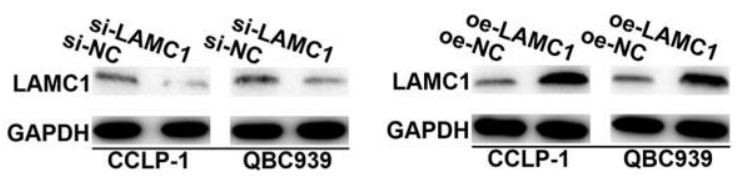

D

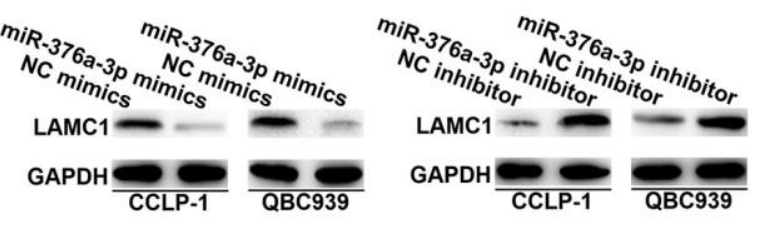

G

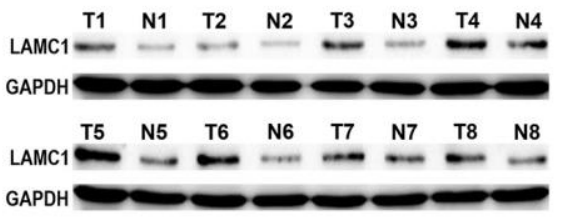

K

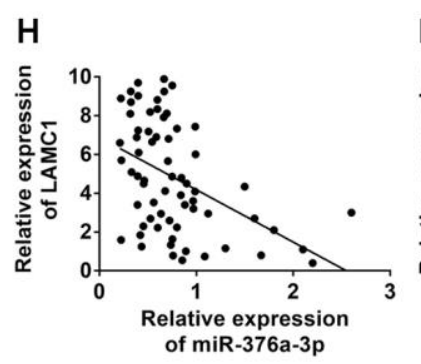

I

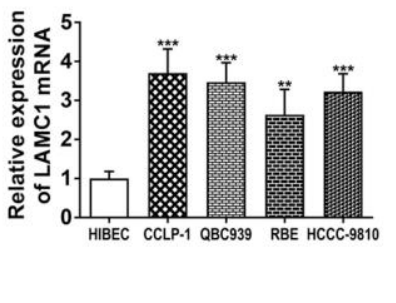

L

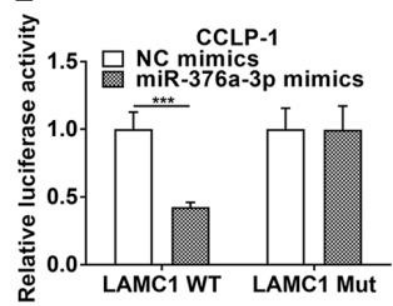

$\mathbf{J}$

Figure 6. LAMC1 is directly restrained by miR-376a-3p. (A) Knockdown efficiency and amplification efficiency of LAMC1 in CCA cells both at mRNA and (B) protein level. (C) miR-376a-3p regulated LAMC1 expression both at mRNA and (D) protein level. (E) LAMC1 expression in TCGA database. (F) The expression of LAMC1 in CCA tissues both at mRNA and (G) protein level. (H) LAMC1 expression was negatively correlated with miR-376a-3p expression. (I) The expression of LAMC1 in CCA cells both at mRNA and (J) protein level. (K) The wild type and mutant type of LAMC1 3'UTR were cloned into luciferase reporter plasmids, respectively. (L) The miR-376a-3p mimics reduced the luciferase activity of LAMC1 wild type rather than mutant type. (M) RIP assay uncovered that LAMC1 was enriched by antiAGO2 antibodies with miR-376a-3p mimics in CCA cells. ${ }^{* *} P<0.01,{ }^{* * *} P<0.001$. 
with miR-376a-3p mimics (Figure 6M). Above findings illustrate that miR-376a-3p directly binds to LAMC1 and restrains its expression in CCA cells. Besides, we detected influence of LAMC1 on malignant biological behaviors of cholangiocarcinoma, and corroborated that downregulated LAMC1 repressed cellular growth and metastasis, whereas upregulated LAMC1 facilitated these malignant biological behaviors (Figure 7).
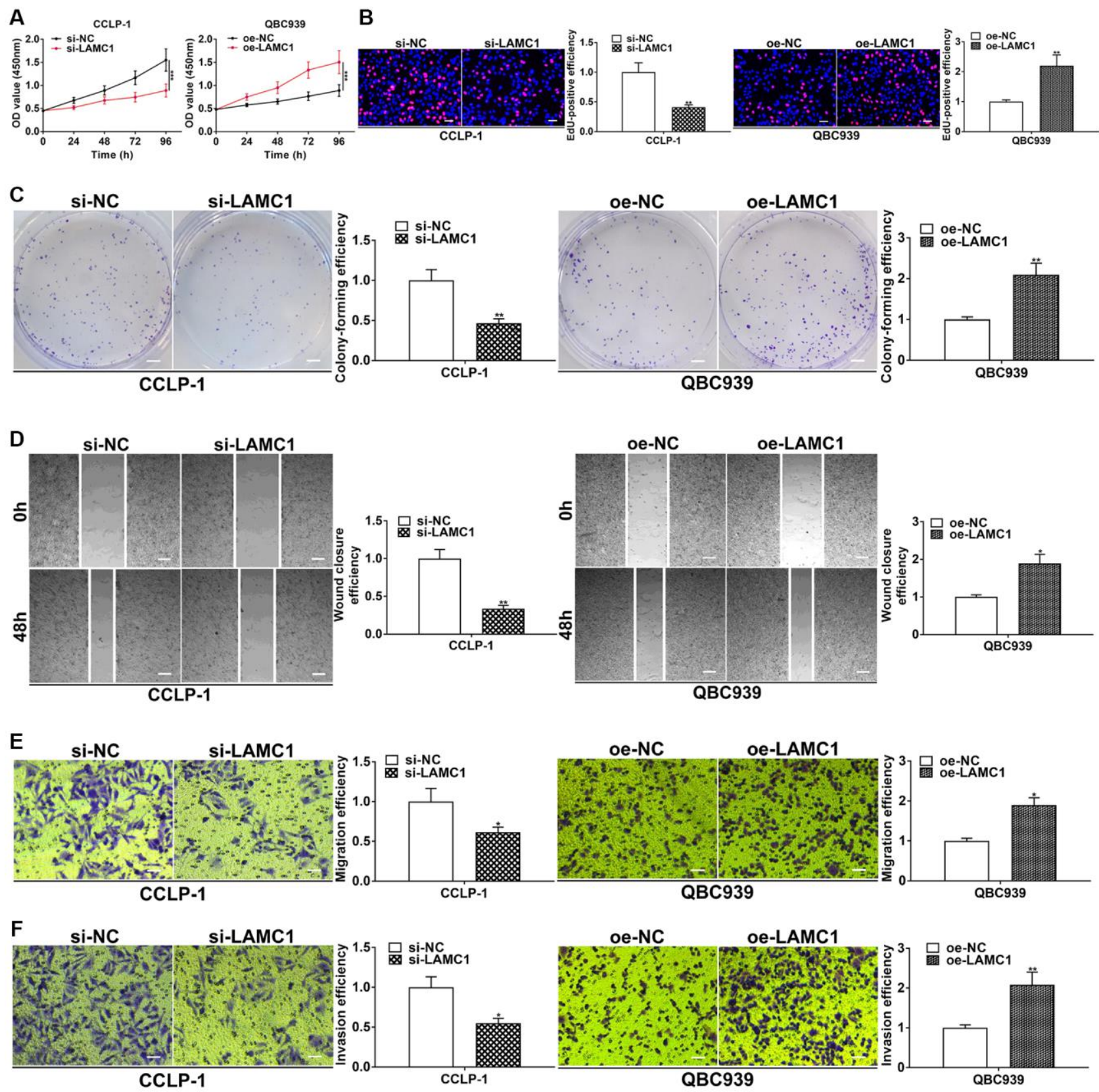

G
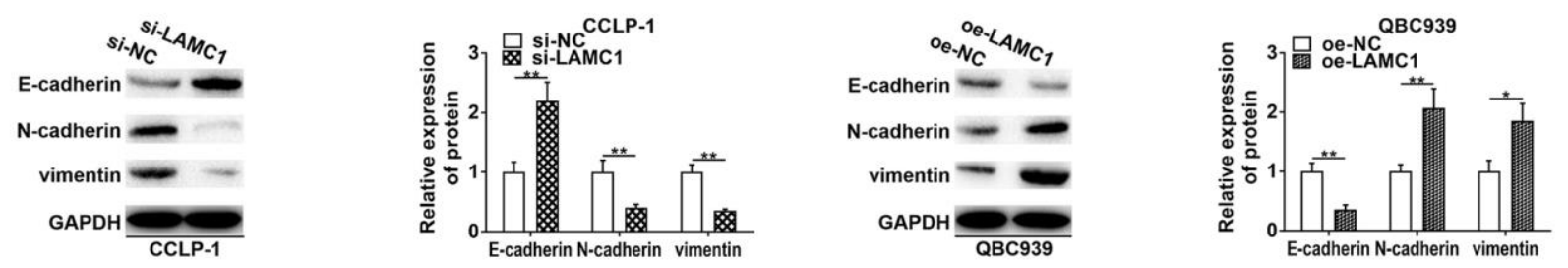

Figure 7. LAMC1 facilitates CCA cell proliferation, invasion and EMT. (A) CCK-8 and (B) EdU assays determined the effect of LAMC1 on CCA proliferation. (C) Colony formation assay determined the effect of LAMC1 on colony-forming ability of CCA cells. (D) Wound healing and $(\mathbf{E}, \mathbf{F})$ transwell assays validated the effects of LAMC1 on migration and invasion of CCA cells. (G) The effect of LAMC1 on EMT process of CCA cells. ${ }^{*} P<0.05,{ }^{* *} P<0.01,{ }^{* * *} P<0.001$. 


\section{PSMA3-AS1 increased LAMC1 through adsorbing miR-376a-3p to promote CCA progression}

To further confirm that PSMA3-AS1 regulated miR376a-3p/LAMC1 to boost CCA development, we performed rescue experiments. As presented in Figure 8A and 8B, silencing PSMA3-AS1 inhibited LAMC1 expression in CCA cells, but reducing miR-376a-3p rescued this process. On the contrary, overexpression of PSMA3-AS1 promoted LAMC1 expression, whereas
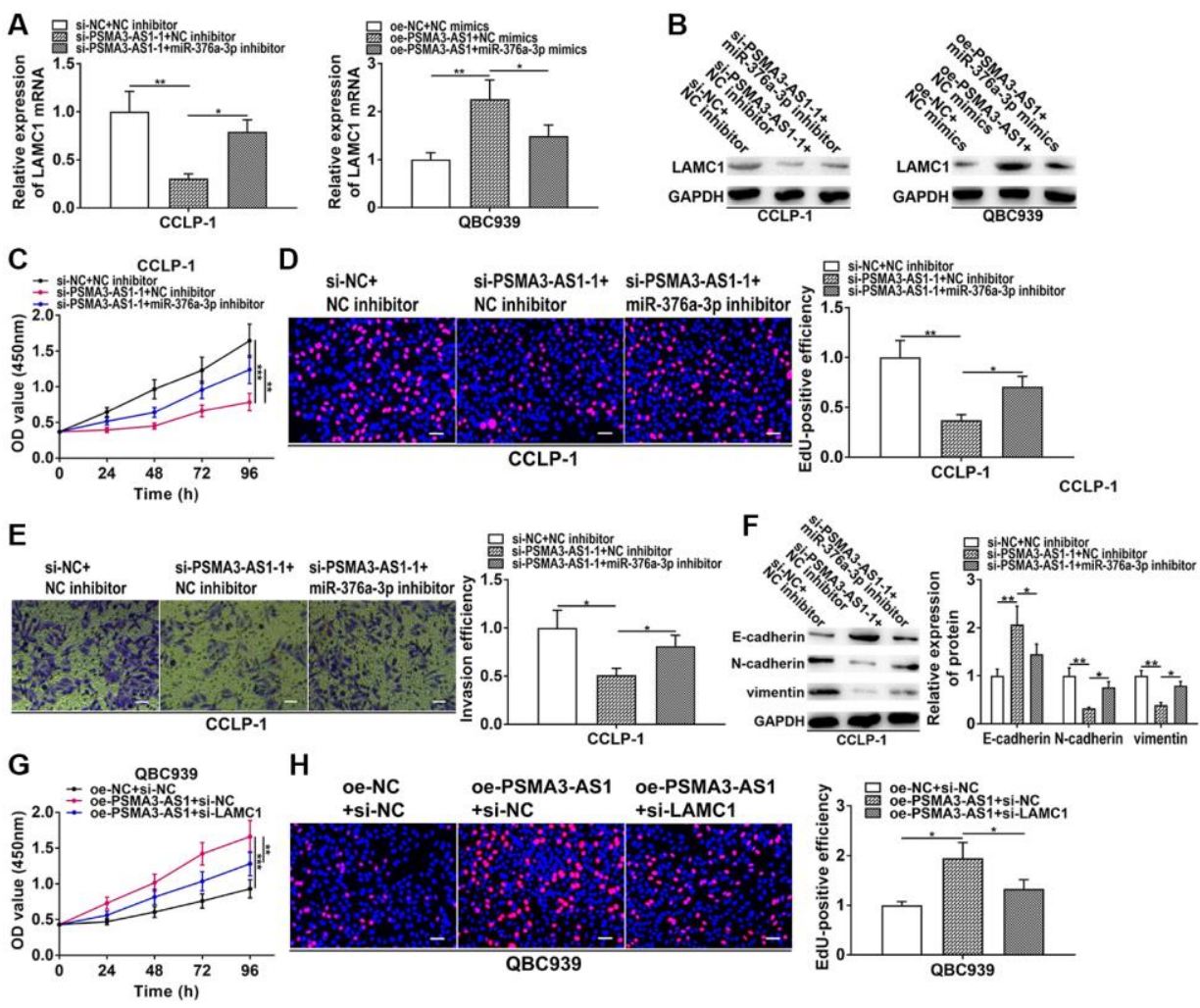

H
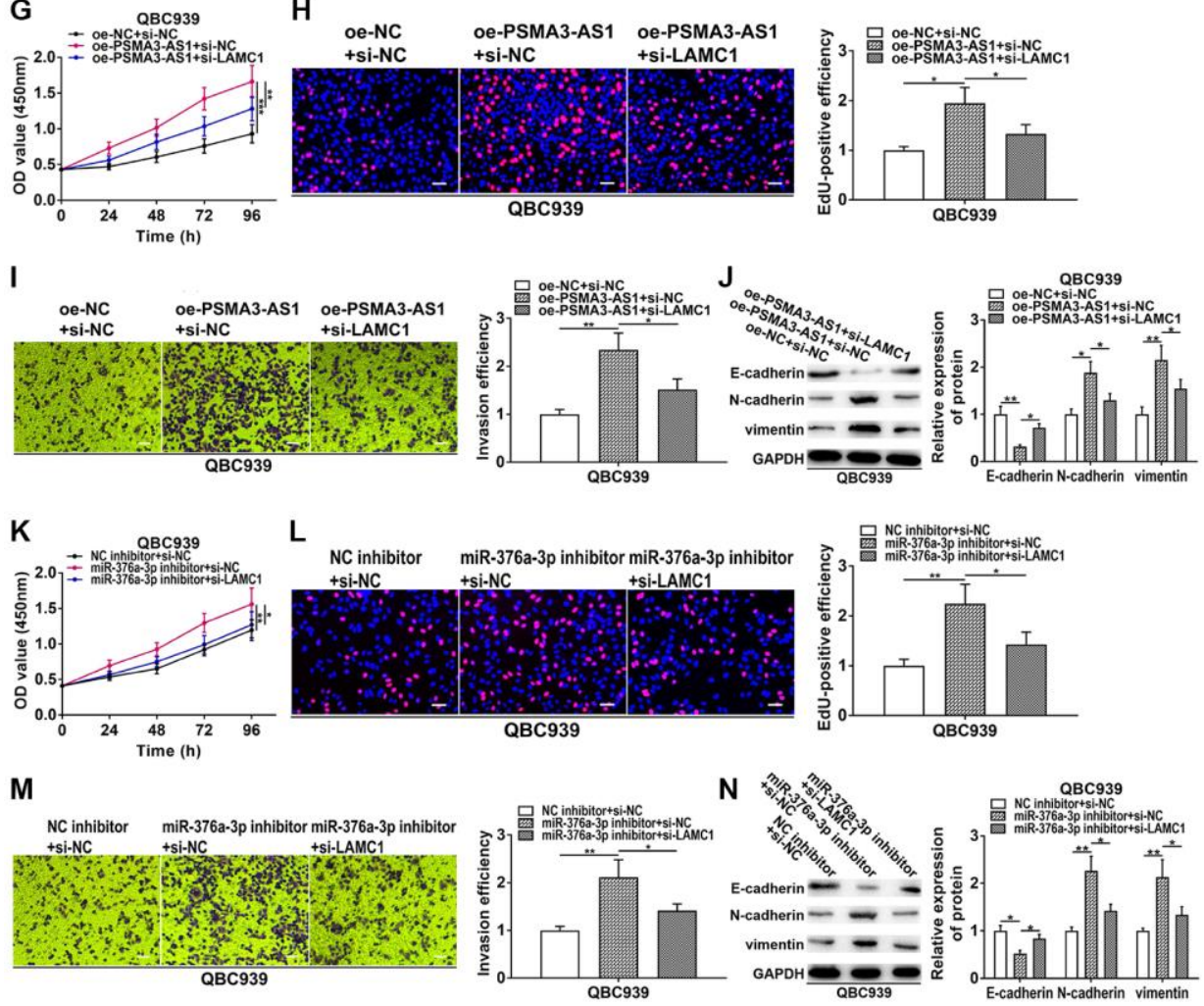

Figure 8. PSMA3-AS1 up-regulates LAMC1 by sponging miR-376a-3p to accelerate CCA development. (A, B) Knockdown of PSMA3-AS1 inhibited LAMC1 expression in CCA cells, but co-transfection of miR-376a-3p inhibitor rescued this process. On the contrary, overexpression of PSMA3-AS1 promoted LAMC1 expression, whereas co-transfection of miR-376a-3p mimics could save the promoting effect caused by PSMA3-AS1 overexpression. (C-F) Knocking down miR-376a-3p could reverse the inhibition of proliferation, invasion and EMT caused by PSMA3-AS1 knockdown. (G-J) Downregulated LAMC1 could rescue the promotion of proliferation, invasion and EMT generated by PSMA3-AS1 overexpression. (K-N) Knocking down miR-376a-3p promoted the proliferation, invasion and EMT process of CCA cells, however, these promotive effects were attenuated by LAMC1 knockdown. ${ }^{*} P<0.05,{ }^{* *} P<0.01,{ }^{* * *} P<0.001$. 
co-transfection of miR-376a-3p mimics could save promoting influence caused by PSMA3-AS1 overexpression. In CCK-8 and EdU experiments, knocking down miR-376a-3p could reverse the proliferative inhibition generated via silencing PSMA3AS1 (Figure 8C, 8D). In transwell and EMT assays, restoration of miR-376a-3p rescued suppression of metastasis and EMT induced via silencing PSMA3-AS1 (Figure 8E, 8F). Moreover, downregulated LAMC1 could rescue facilitation of growth, metastasis and EMT induced by PSMA3-AS1 overexpression (Figure 8G$8 \mathrm{~J})$. In addition, knocking down miR-376a-3p boosted cellular malignant process, nevertheless, the boosting influence was weakened via silencing LAMC1 (Figure $8 \mathrm{~K}-8 \mathrm{~N})$. These results suggest that PSMA3-AS1 boosts cholangiocarcinoma proliferation and metastasis by modulating miR-376a-3p/LAMC1.

\section{DISCUSSION}

In recent years, a good deal of researches have revealed that IncRNAs were deregulated in malignant tumors, and became targets for diagnosing and treating cancers, including cholangiocarcinoma [7]. LncRNAs play a role of oncogene or tumor suppressor gene in CCA [18]. Some researches have demonstrated that PSMA3-AS1 exerted cancer-promoting function in some types of tumors [19]. Nevertheless, specific action of PSMA3AS1 in CCA is unknown. Using the TCGA database, we found abnormally increased PSMA3-AS1 in CCA. It was confirmed via RT-qPCR that PSMA3-AS1 was indeed elevated in cholangiocarcinoma, and significantly linked to worse survival. This is consistent with trends in previous studies. Analysis of PSMA3AS1 as a prognostic assessment indicator also displayed its satisfactory sensitivity and specificity. Proliferation and invasion are common and important biological behaviors of tumors [20]. In this study, we performed loss-of-function and gain-of-function experiments to confirm that PSMA3-AS1 boosted CCA growth, invasion and EMT process. These suggest that PSMA3AS1 is not only abnormally highly expressed, but also plays a tumor-promoting role in CCA.

LncRNAs can be involved in gene regulation at epigenetic, transcriptional and post-transcriptional stages through multiple complex molecular mechanisms $[8,21$, 22]. PSMA3-AS1 is predominantly expressed in CCA cytoplasm, so we evaluated whether it promotes CCA progression at posttranscriptional level through the ceRNA mechanism. In ceRNA pattern, IncRNAs modulate target genes via competitively binding miRNA [23]. Predicted by the bioinformatic database, we found that PSMA3-AS1 and LAMC1 possessed overlapping binding site of miR-376a-3p. After that, we verified that LAMC1 was enhanced in cholangiocarcinoma and boosted cellular malignant progress. In terms of mechanisms, we confirmed that PSMA3-AS1 upregulated LAMC1 by sponging of miR-376a-3p, thereby expediting cholangiocarcinoma deterioration. Rescue assays further confirmed that PSMA3-AS1 boosted CCA growth and metastasis by regulating miR-376a-3p/LAMC1 .

PAX5 is an important cancer-related transcription factor. Previous studies have demonstrated that PAX5 was deregulated in a variety of tumors and involved in malignant biological behaviors such as proliferation and metastasis [14]. By JASPAR database analysis, we found PAX5 binding sites in the PSMA3-AS1 promoter region, and that the relative score was high. According to the literatures, PAX5 as a transcription factor could activate lncRNA transcription, including IDH1-AS1 [15], FOXP4-AS1 [24], LINC01194 [25], UASR1 [26]. Therefore, we attempted to detect the effect of PAX5 on the regulation of PSMA3-AS1 expression. As predicted, we confirmed that the transcription factor PAX5 enhanced PSMA3-AS1 expression by binding to its promoter region. In addition, PAX5 promoted EMT process and LAMC1 expression in CCA. Accordingly, PAX5-induced PSMA3-AS1 boosted occurrence and development of cholangiocarcinoma via mediating miR-376a-3p/LAMC1.

In conclusion, the study reveals that PSMA3-AS1 represents a new cancer-promoting lncRNA in cholangiocarcinoma. PSMA3-AS1 is remarkably increased in CCA and its overexpression presages a terrible prognosis. PAX5-mediated PSMA3-AS1 elevates LAMC1 through adsorbing miR-376a-3p, thereby facilitating cellular growth and metastasis. The present research uncovers that PAX5/PSMA3-AS1/miR-376a3p/LAMC1 expedites cholangiocarcinoma deterioration, and PSMA3-AS1 is hopeful to become an intervention target for cholangiocarcinoma.

\section{MATERIALS AND METHODS}

\section{Clinical specimens}

$66 \mathrm{CCA}$ tissues and matched adjoining non-cancerous bile duct tissues from The 2nd Affiliated Hospital of Harbin Medical University were gathered. The patients had no preoperative radiotherapy and chemotherapy. Collected specimens were promptly placed into liquid nitrogen. Clinical research has been authorized via Ethics Committee of Hospital. Participators signed the informed consent form.

\section{Cellular cultivation and interference}

HCCC-9810, QBC939, RBE, CCLP-1 and normal HIBEC were applied in this study. Cell was incubated in 
RPMI-1640 and DMEM with 10\% FBS (Invitrogen, Carlsbad, CA, USA). SiRNA was applied for knockdown of the target genes, and pcDNA3.1 plasmid was applied for overexpression. They were all purchased from GenePharma (Shanghai, China). Transfection was performed using Lipofectamine 3000 (Invitrogen). SiRNAs were shown in the Supplementary Table 1.

\section{RT-qPCR}

RNAs were extracted via TRIzol (Invitrogen). PrimeScript ${ }^{\mathrm{TM}}$ RT Master Mix kit (Takara, Shiga, Japan) was applied for reverse transcription. Finally, RT-qPCR was carried out via SYBR Premix DimerEraser kit (Takara) with ABI Prism 7300 Thermal Cycler (Applied Biosystems, Foster City, CA, USA). GAPDH and U6 were treated as controls. PCR primer sequences were listed in the Supplementary Table 1.

\section{CCK-8 experiment}

Cellular proliferative ability was detected via CCK-8 experiment. $3 \times 10^{3}$ cells were inoculated into 96-well plates. $10 \mu \mathrm{L}$ CCK-8 reagent (Dojindo, Kumamoto, Japan) was dropped in each well for 2 hours. Absorbance of each well at $450 \mathrm{~nm}$ was identified every 24 hours.

\section{Colony formation experiment}

Cell was inoculated in 6-well plate, and then incubated for 2 weeks. The culture was terminated when visible colonies formed. Colony was soaked in formaldehyde and dyed using crystal violet (Beyotime, Beijing, China) for $30 \mathrm{~min}$. Staining diluent was slowly eluted, and colonies were calculated.

\section{EdU experiment}

The EdU kit (Ribobio, Guangzhou, China) was applied to perform EdU incorporation assay. CCA cell was cultivated using $100 \mu \mathrm{L} \mathrm{EdU}$ at $37^{\circ} \mathrm{C}$ for 2 hours, and dyed successively by Apollo and Hoechst.

\section{Subcutaneous tumor formation experiment}

6-week-old female BALB/c nude mice (Vital River Laboratory Animal Technology Co., Ltd., Beijing, China) were kept in a SPF grade place. Animal research has been authorized via Animal Care and Use Committee of The Second Affiliated Hospital of Harbin Medical University. A total of $5 \times 10^{6}$ CCLP-1 suspension was subcutaneously inoculated into posterior flank of mouse. Xenograft volume was assessed using $0.5 \times$ length $\times$ width $^{2}$ per 5 days. Xenograft weight was assessed after 20 days.

\section{Wound healing assay}

For migration assay, CCA cell was inoculated into the 6-well plate. When cells reached $90 \%$ confluence, a straight wound was produced using a pipette tip. Then cells were incubated for 48 hours without serum. The wound width was detected at 0 and 48 hours using a microscope, and the migratory ability was evaluated according to the relative wound width.

\section{Transwell assay}

CCA cells in $200 \mu \mathrm{L}$ serum-free medium were inoculated in superior chamber (Corning Incorporated, Corning, NY, USA) that was inserted in a 24-well plate with $600 \mu \mathrm{L}$ complete medium in the bottom. After incubation for 24 hours, bottom cell was reacted in formaldehyde and dyed using crystal violet. Invasion experiment was similarly executed in chamber precoated with diluted Matrigel (BD Biosciences, San Jose, CA, USA).

\section{Western blotting}

The sample was lysed in RIPA (Beyotime) and the lysates were collected after centrifugation for $15 \mathrm{~min}$ at $12000 \mathrm{r} / \mathrm{min}$. Afterwards, protein concentration was measured via BCA (Beyotime). After separation via SDS-PAGE, sample was semi-dry transferred to PVDF membrane (Millipore, Billerica, MA, USA), and then transferred PVDF was soaked using 5\% nonfat milk for 2 hours. Subsequently, primary antibody (Abcam, Cambridge, MA) soaked PVDF overnight at $4^{\circ} \mathrm{C}$. Secondary antibody (Abcam) soaked PVDF for 1.5 hours.

\section{ChIP assay}

The purpose of ChIP assay (Millipore) is to detect whether the transcription factor PAX5 binds to PSMA3AS1 promoter region. For produce of DNA-protein cross-links, formaldehyde treatment was conducted on CCA cells. The sonication of cell lysates was used for generating chromatin fragments. Then specific antibodies were used to immunoprecipitate the lysates, and IgG was deemed as control. RT-qPCR was performed to examine precipitated chromatin DNA. The PCR primers were presented in the Supplementary Table 1.

\section{Luciferase reporter experiment}

The purpose of this assay is to examine the interaction of PAX5 with the DNA fragment of the PSMA3-AS1 promoter. This assay is also used to validate binding capacity of miR-376a-3p to PSMA3-AS1/LAMC1. 
Wild-type (WT) and mutant-type (Mut) plasmids were designed and inserted into pmirGLO reporter vector (Promega, Madison, WI, USA). miR-376a-3p mimics/NC or oe-PAX5/NC was co-transfected with the WT or Mut luciferase plasmids into CCA cell. Luciferase activity was estimated using a dualluciferase reporter kit (Promega) after 48 hours.

\section{RIP assay}

The aim of AGO2 RIP assay (Millipore) is to affirm interreaction of miR-376a-3p and PSMA3AS1/LAMC1. Briefly, RIP lysis buffer was applied to lyse CCA cells. Whereafter, RNA was immunoprecipitated via magnetic beads conjugated with anti-AGO2 antibody (Millipore) or IgG. Purified RNA was measured by RT-qPCR.

\section{Statistical analysis}

Data were presented as mean \pm SD and analyzed via GraphPad 7.0 and SPSS 20.0. Student's $t$-test and ANOVA were used to analyze differences. $P<0.05$ was considered to indicate a statistically significant difference.

\section{AUTHOR CONTRIBUTIONS}

Conceptualization: Dongsheng Sun; experimental design and execution: Dongsheng Sun, Fujun $\mathrm{Li}$ and Lang Liu; data curation and analysis: Shaobo Yu and Haicun Wang; experimental resources: Xingming Jiang; writing-original draft: Xin Gao and Guanglin Liu; writing-review and editing: Yuqiao Zhao and Gongcai Qiu; supervision: Xingming Jiang.

\section{CONFLICTS OF INTEREST}

The authors declare no conflicts of interest related to this study.

\section{FUNDING}

This study was funded by National Natural Science Foundation of Heilongjiang Province (NO. LH2020H058); Chen Xiaoping Foundation for the Development of Science and Technology of Hubei Province (NO. CXPJJH12000002-2020015).

\section{REFERENCES}

1. Razumilava N, Gores GJ. Cholangiocarcinoma. Lancet. 2014; 383:2168-79. https://doi.org/10.1016/S0140-6736(13)61903-0 PMID:24581682
2. Buckholz AP, Brown RS Jr. Cholangiocarcinoma: Diagnosis and Management. Clin Liver Dis. 2020; 24:421-36.

https://doi.org/10.1016/i.cld.2020.04.005 PMID:32620281

3. Bergquist A, von Seth E. Epidemiology of cholangiocarcinoma. Best Pract Res Clin Gastroenterol. 2015; 29:221-32. https://doi.org/10.1016/i.bpg.2015.02.003 PMID:25966423

4. Li J, Jiang X, Li Z, Huang L, Ji D, Yu L, Zhou Y, Cui Y. SP1induced HOXD-AS1 promotes malignant progression of cholangiocarcinoma by regulating miR-520c3p/MYCN. Aging (Albany NY). 2020; 12:16304-25. https://doi.org/10.18632/aging.103660 PMID:32857725

5. Peng WX, Koirala P, Mo YY. LncRNA-mediated regulation of cell signaling in cancer. Oncogene. 2017; 36:5661-7.

https://doi.org/10.1038/onc.2017.184 PMID:28604750

6. Li J, Guan C, Hu Z, Liu L, Su Z, Kang P, Jiang X, Cui Y. Yin Yang 1-induced LINC00667 up-regulates pyruvate dehydrogenase kinase 1 to promote proliferation, migration and invasion of cholangiocarcinoma cells by sponging miR-200c-3p. Hum Cell. 2021; 34:187-200. https://doi.org/10.1007/s13577-020-00448-1 PMID:33040228

7. Li J, Huang L, Li Z, Zhong X, Tai S, Jiang X, Cui Y. Functions and roles of long noncoding RNA in cholangiocarcinoma. J Cell Physiol. 2019; 234:17113-26. https://doi.org/10.1002/icp.28470 PMID: 30888066

8. Li J, Jiang X, Li C, Liu Y, Kang P, Zhong X, Cui Y. LncRNA-MEG3 inhibits cell proliferation and invasion by modulating Bmi1/RNF2 in cholangiocarcinoma. J Cell Physiol. 2019; 234:22947-59. https://doi.org/10.1002/jcp.28856 PMID:31119760

9. Xu H, Han H, Song S, Yi N, Qian C, Qiu Y, Zhou W, Hong $\mathrm{Y}$, Zhuang W, Li Z, Li B, Zhuang W. ExosomeTransmitted PSMA3 and PSMA3-AS1 Promote Proteasome Inhibitor Resistance in Multiple Myeloma. Clin Cancer Res. 2019; 25:1923-35. https://doi.org/10.1158/1078-0432.CCR-18-2363 PMID:30610101

10. Peng $P$, Wang $Y$, Wang $B L$, Song $Y H$, Fang $Y$, Ji $H$, Huangfu CN, Wang KM, Zheng Q. LncRNA PSMA3-AS1 promotes colorectal cancer cell migration and invasion via regulating miR-4429. Eur Rev Med Pharmacol Sci. 2020; 24:11594-601. 
https://doi.org/10.26355/eurrev 20201123802 PMID:33275226

11. Qiu BQ, Lin XH, Ye XD, Huang $W$, Pei X, Xiong D, Long $X$, Zhu SQ, Lu F, Lin K, Zhang XQ, Xu JJ, Sheng LL, et al. Long non-coding RNA PSMA3-AS1 promotes malignant phenotypes of esophageal cancer by modulating the miR-101/EZH2 axis as a ceRNA. Aging (Albany NY). 2020; 12:1843-56.

https://doi.org/10.18632/aging.102716

PMID: 32005028

12. Huang $T$, Chen $Y$, Zeng $Y, X u$ C, Huang J, Hu W, Chen $\mathrm{X}, \mathrm{Fu} \mathrm{H}$. Long non-coding RNA PSMA3-AS1 promotes glioma progression through modulating the miR-4113p/HOXA10 pathway. BMC Cancer. 2021; 21:844. https://doi.org/10.1186/s12885-021-08465-5 PMID: 34294084

13. Shahjahani M, Norozi $F$, Ahmadzadeh A, Shahrabi S, Tavakoli F, Asnafi AA, Saki N. The role of Pax5 in leukemia: diagnosis and prognosis significance. Med Oncol. 2015; 32:360.

https://doi.org/10.1007/s12032-014-0360-6 PMID:25428382

14. Crapoulet N, O'Brien P, Ouellette RJ, Robichaud GA. Coordinated expression of Pax-5 and FAK1 in metastasis. Anticancer Agents Med Chem. 2011; 11:643-9.

https://doi.org/10.2174/187152011796817637 PMID:21707507

15. Zhang N, Li Z, Bai F, Zhang S. PAX5-induced upregulation of IDH1-AS1 promotes tumor growth in prostate cancer by regulating ATG5-mediated autophagy. Cell Death Dis. 2019; 10:734.

https://doi.org/10.1038/s41419-019-1932-3 PMID:31570703

16. Lou J, Gong J, Ke J, Tian J, Zhang Y, Li J, Yang Y, Zhu Y, Gong Y, Li L, Chang J, Zhong R, Miao X. A functional polymorphism located at transcription factor binding sites, rs6695837 near LAMC1 gene, confers risk of colorectal cancer in Chinese populations. Carcinogenesis. 2017; 38:177-83.

https://doi.org/10.1093/carcin/bgw204 PMID:28039327

17. Ye G, Qin Y, Wang S, Pan D, Xu S, Wu C, Wang X, Wang J, Ye H, Shen H. Lamc1 promotes the Warburg effect in hepatocellular carcinoma cells by regulating PKM2 expression through AKT pathway. Cancer Biol Ther. 2019; 20:711-9.

https://doi.org/10.1080/15384047.2018.1564558 PMID:30755064

18. Ma Y, Zhang J, Wen L, Lin A. Membrane-lipid associated IncRNA: A new regulator in cancer signaling. Cancer Lett. 2018; 419:27-9. https://doi.org/10.1016/i.canlet.2018.01.008 PMID:29330108

19. Li F, Yu L, Zhu J. LncRNA PSMA3-AS1 Promotes Lung Cancer Growth and Invasion via Sponging MiR-4504.

Cancer Manag Res. 2020; 12:5277-83.

https://doi.org/10.2147/CMAR.S253575

PMID:32669876

20. Xie Q, Mittal S, Berens ME. Targeting adaptive glioblastoma: an overview of proliferation and invasion. Neuro Oncol. 2014; 16:1575-84. https://doi.org/10.1093/neuonc/nou147 PMID:25082799

21. Wang C, Wang L, Ding Y, Lu X, Zhang G, Yang J, Zheng $H$, Wang $H$, Jiang $Y, X u$ L. LncRNA Structural Characteristics in Epigenetic Regulation. Int J Mol Sci. 2017; 18:2659.

https://doi.org/10.3390/ijms18122659

PMID:29292750

22. Raziq K, Cai M, Dong K, Wang P, Afrifa J, Fu S. Competitive endogenous network of IncRNA, miRNA, and $\mathrm{mRNA}$ in the chemoresistance of gastrointestinal tract adenocarcinomas. Biomed Pharmacother. 2020; 130:110570.

https://doi.org/10.1016/j.biopha.2020.110570 PMID:32763816

23. Tay Y, Rinn J, Pandolfi PP. The multilayered complexity of ceRNA crosstalk and competition. Nature. 2014; 505:344-52.

https://doi.org/10.1038/nature12986

PMID:24429633

24. Wu X, Xiao Y, Zhou Y, Zhou Z, Yan W. LncRNA FOXP4AS1 is activated by PAX5 and promotes the growth of prostate cancer by sequestering miR-3184-5p to upregulate FOXP4. Cell Death Dis. 2019; 10:472. https://doi.org/10.1038/s41419-019-1699-6 PMID:31209207

25. Song HR, Guo XB, Duan Y, Meng HY, Wang ZY. PAX5induced upregulation of LINC01194 exerts oncogenic properties by regulating GOLPH3 expression via miR486-5p in prostate cancer. Eur Rev Med Pharmacol Sci. 2021; 25:2528-41.

https://doi.org/10.26355/eurrev 202103 25416

PMID:33829439

26. Wang W, Wang Z, Wang H, Li X, Wang HT. Promoting effect of PAX5-activated IncRNA UASR1 on growth of colorectal cancer by regulating the MTOR pathway. Eur Rev Med Pharmacol Sci. 2020; 24:2986-93. https://doi.org/10.26355/eurrev 20200320663 PMID: $\underline{32271416}$ 


\section{SUPPLEMENTARY MATERIALS}

\section{Supplementary Figure}

A

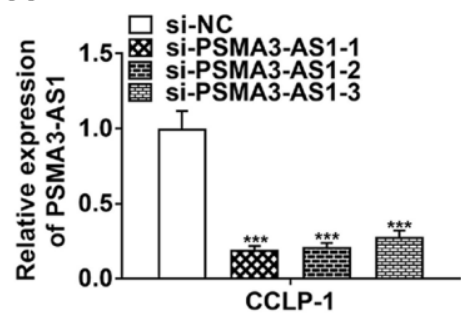

C

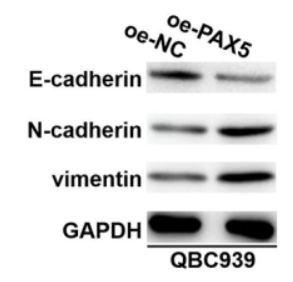

E

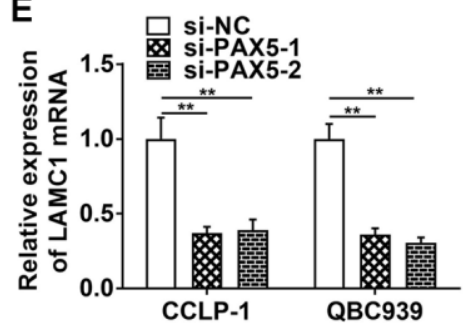

$\mathbf{F}$

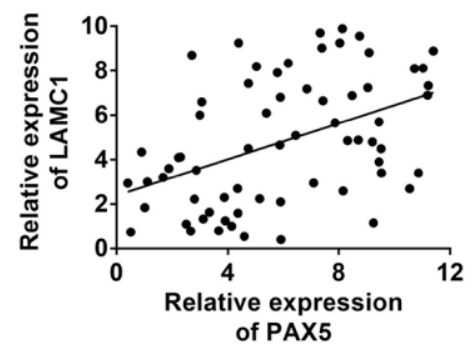

B
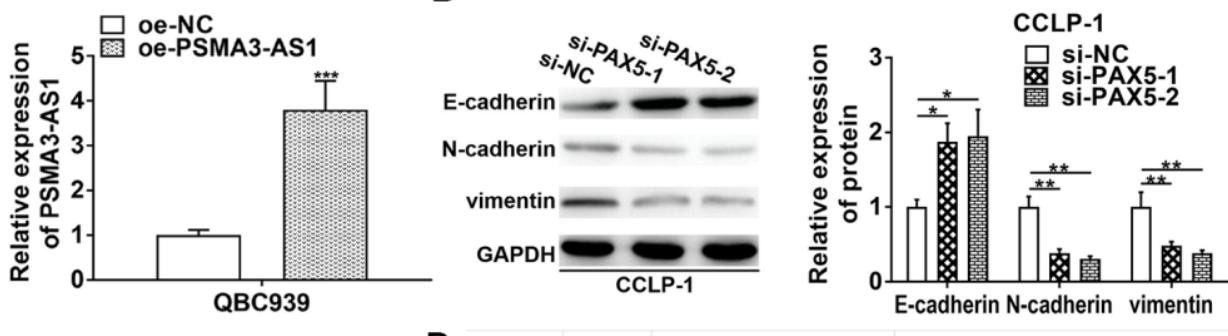

GeneName Gene Type TargetSite

Alignment

PSMA3- antisense chr14:58733629-58733649[-] Target: 5' aaauccacagcCAUCUAUGAa $3^{\prime}$ AS1

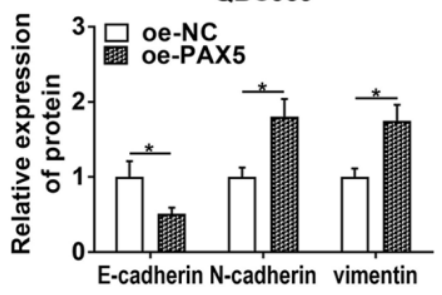

Binding Site of hsa-miR-376a-3p on LAMC1:

Show $10 \vee$ entries

Bindingsite

†. Class Alignment

chr1:183112322-183112328[+]

$8 \mathrm{mer}$

Target: 5, caguacucuUGuvUCUAUGAa 3 II :: :IIIIII
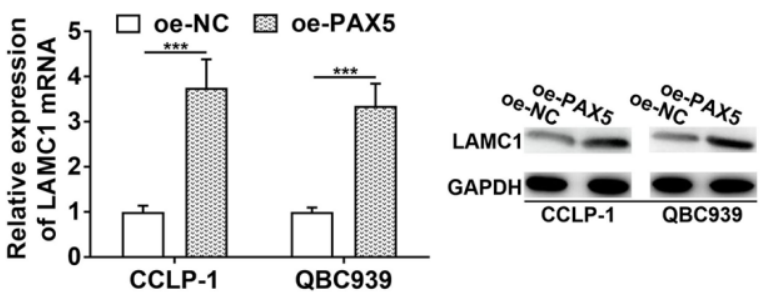

Supplementary Figure 1. PAX5 promotes EMT process and LAMC1 expression in CCA. (A) Knockdown efficiency and amplification efficiency of PSMA3-AS1. (B) Silencing PAX5 inhibited the EMT process in CCLP-1 cells, and (C) overexpressing PAX5 promoted EMT process in QBC939 cells. (D) StarBase v3.0 database showed that PSMA3-AS1 had overlapping binding sites with LAMC1 at miR-376a$3 p$ sequences. (E) PAX5 promoted LAMC1 expression both at mRNA and protein level in CCA. (F) PAX5 expression was positively related to LAMC1 expression in CCA. ${ }^{*} P<0.05,{ }^{* *} P<0.01,{ }^{* * *} P<0.001$. 


\section{Supplementary Table}

Supplementary Table 1. Primers and siRNAs used in this study.

\begin{tabular}{|c|c|}
\hline Names & Sequences $\left(5^{\prime}\right.$ to $\left.3^{\prime}\right)$ \\
\hline PSMA3-AS1 & $\begin{array}{l}\text { F: 5'-AACAGACCATCAGAAGAGAACA-3' } \\
\text { R: 5'-GAACAGAAACCAGAGCCATACA-3' }\end{array}$ \\
\hline LAMC1 & $\begin{array}{l}\text { F: 5'-ACTCCTAATCTTGGACCATAC-3' } \\
\text { R: 5'-ACAACAGCACAACTTGAAC-3' }\end{array}$ \\
\hline PAX5 & $\begin{array}{l}\text { F: 5'-ACTTGCTCATCAAGGTGTCAG-3' } \\
\text { R: 5'-TCCTCCAATTACCCCAGGCTT-3' }\end{array}$ \\
\hline GAPDH & $\begin{array}{l}\text { F: 5'-GACAGTCAGCCGCATCTTCT-3' } \\
\text { R: 5'-TTAAAAGCAGCCCTGGTGAC-3' }\end{array}$ \\
\hline U6 & $\begin{array}{l}\text { F: 5'-CTCGCTTCGGCAGCACA-3' } \\
\text { R: 5'-AACGCTTCACGAATTTGCGT-3' }\end{array}$ \\
\hline $\operatorname{miR}-376 a-3 p$ & $\begin{array}{l}\text { F: 5'-TGCACCTAAAAGGAG-3' } \\
\text { R: 5'-GTGCAGGGTCCGAGGT-3' }\end{array}$ \\
\hline miR-107 & $\begin{array}{l}\text { F: 5'-GCCGAATTCAAAGCGAGATTCCATCAGCA-3' } \\
\text { R: 5'-GCCGGATCCTGTCAACCCAGAACT-CAAAGG-3' }\end{array}$ \\
\hline $\operatorname{miR}-135-5 p$ & $\begin{array}{l}\text { F: 5'-AGCATAATACAGCAGGCACAGAC-3' } \\
\text { R: 5'-AAAGGTTGTTCTCCACTCTCTCAC-3' }\end{array}$ \\
\hline $\operatorname{miR}-205-5 p$ & $\begin{array}{l}\text { F: 5'-TCCTTCATTCCACCGGAGTCTG-3' } \\
\text { R: 5'-GCGAGCACAGAATTAATACGAC-3' }\end{array}$ \\
\hline $\operatorname{miR}-218-5 p$ & $\begin{array}{l}\text { F: 5'-TTGCGGATGGTTCCGTCAAGCA-3' } \\
\text { R: 5'-ATCCAGTGCAGGGTCCGAGG-3' }\end{array}$ \\
\hline $\operatorname{miR}-448$ & $\begin{array}{l}\text { F: 5'-TTATTGCGATGTGTTCCTTATG-3' } \\
\text { R: 5'-ATGCATGCCACGGGCATATACACT-3' }\end{array}$ \\
\hline $\operatorname{miR}-9-5 p$ & $\begin{array}{l}\text { F: 5'-GTGCAGGGTCCGAGGT-3' } \\
\text { R: 5'-GCGCTCTTTGGTTATCTAGC-3' }\end{array}$ \\
\hline PSMA3-AS1 promoter binding site 1 & $\begin{array}{l}\text { F: 5'-GGTAGCGAGGTCCTATCCGA-3' } \\
\text { R: 5'-GTATCCCCGGATTCCCCTCT-3' }\end{array}$ \\
\hline PSMA3-AS1 promoter binding site 2 & $\begin{array}{l}\text { F: 5'-GGGAGAGGGATGCTAGGCAA-3' } \\
\text { R: 5'-CGCCCGCCTCAACTTTTTG-3' }\end{array}$ \\
\hline si-PSMA3-AS1-1 & 5'-CCAGCAUCAAGAUGAUUUA-3' \\
\hline si-PSMA3-AS1-2 & 5'-UCUCGAAAACCCGAAAGAGAA-3' \\
\hline si-PSMA3-AS1-3 & 5'-GGCCUAAGAAUCUCUUGAA-3' \\
\hline si-PAX5-1 & 5'-GCAGUCUGUUCUGAACAUA-3' \\
\hline si-PAX5-2 & 5'-CAAAGGAUAGUGGAACUUG-3' \\
\hline si-LAMC1 & 5'-UCAUCAAUCUGAAAGGUAGAG-3' \\
\hline
\end{tabular}

